\title{
Chrysobalanaceae endémicas del Perú
}

\section{Blanca León ${ }^{1,2}$}

${ }^{1}$ Museo de Historia Natural, Av. Arenales 1256, Aptdo. 14-0434, Lima 14, Perú

2 Plant Resources Center, University of Texas at Austin, Austin TX 78712 EE.UU.

blanca.leon@mail.utexas.edu

\section{Resumen}

La familia Chrysobalanaceae es reconocida en el Perú por presentar cuatro géneros y 98 especies (Brako \& Zarucchi, 1993; Ulloa Ulloa et al., 2004), todas ellas árboles y arbustos. En este trabajo reconocemos nueve especies y una variedad como endemismos peruanos en dos géneros. El género Licania es el más rico en especies endémicas. Estos taxones endémicos ocupan la región Bosques Húmedos Amazónicos, entre los 100 y 500 m de altitud. Dos especies endémicas están representadas dentro del Sistema Nacional de Áreas Naturales Protegidas por el Estado.

Palabras claves: Chrysobalanaceae, Licania, Perú, endemismo, plantas endémicas.

\section{Abstract}

The Chrysobalanaceae are represented in Peru by four genera and 98 species (Brako \& Zarucchi, 1993; Ulloa Ulloa et al., 2004), all of them trees and shrubs. Here we recognize as endemics nine species and one variety in two genera. Licania is the genus with the largest number of endemic species. Endemic Chrysobalanaceae are found in the Humid Lowland Amazonian Forests region between 100 and $500 \mathrm{~m}$ elevation. Two endemic species have been found within Peru's protected area system.

Keywords: Chrysobalanaceae, Licania, Peru, endemism, endemic plants.

\section{Hirtella aramangensis Prance}

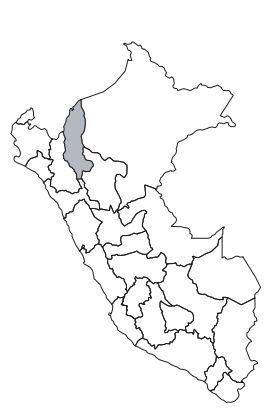

\section{DD}

Publicación: Fl. Neotrop. 9: 315-316, f. 50 D-F. 1972.

Colección tipo: F. Woytkowski 5625

Herbarios: GH, NY, S, US.

Nombre común: Desconocido.

Registro departamental: AM.

Regiones Ecológicas: BHA; $500 \mathrm{~m}$.

SINANPE: Sin registro.

Herbarios peruanos: Ninguno.

Observaciones: Árbol conocido, aparentemente, de la colección tipo, una planta recolectada en la cuenca del Marañón, en la década de 1960.

\section{Hirtella revillae Prance}

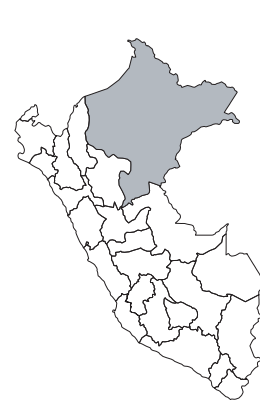

\section{VU, B1ab(iii)}

Publicación: Acta Amazon. 8(4): 587, 589, f. 6.1978.

Colección tipo: A.H. Gentry et al. 15807

Herbarios: MO, NY; AMAZ.

Nombre común: Pucacuro caspi.

Registro departamental: LO.

Regiones Ecológicas: BHA; $120-200 \mathrm{~m}$. SINANPE: RNAM

Herbarios peruanos: AMAZ (isotipo+5).

Observaciones: Árbol conocido de varias poblaciones en la cuenca amazónica. Esta especie está representada en un área protegida (Vásquez, 1997), así como en un arboreto localizado en la cuenca del Ucayali.

\section{Hirtella standleyi Baehni \& J.F. Macbr.}

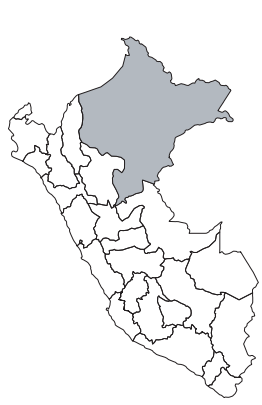

DD

Publicación: Field Mus. Nat. Hist., Bot. Ser. 13(2/3): 1078. 1938.

Colección tipo: G. Klug 3022

Herbarios: A, F, K, NY, S, US.

Nombre común: Desconocido.

Registro departamental: LO.

Regiones Ecológicas: BHA; $220 \mathrm{~m}$.

SINANPE: Sin registro.

Herbarios peruanos: Ninguno.

Observaciones: Árbol conocido aparentemente de una localidad, en el occidente del Departamento de Loreto,de la cuenca del Huallaga. Al parecer, no ha vuelto a ser recolectada desde 1933.

\section{Hirtella subglanduligera Pilg.}

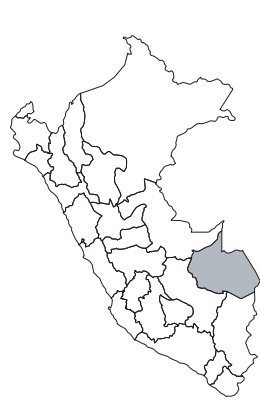

DD

Publicación: Notizbl. Konigl. Bot. Gart. Berlin 6: 140-141. 1914.

Colección tipo: E.H.G. Ule 9414

Herbarios: MG, US.

Nombre común: Desconocido.

Registro departamental: MD.

Regiones Ecológicas: BHA; altitud desconocida.

SINANPE: Sin registro.

Herbarios peruanos: Ninguno.

Observaciones: Esta especie arbórea es conocida sólo de la citación en la descripción original, la cual menciona 'Alto Acre, Seringal Auristella', probablemente una localidad cerca de la frontera con Brasil. Fue recolectada en 1911 y no se conoce de registros adicionales. 


\section{Licania cecidiophora Prance}

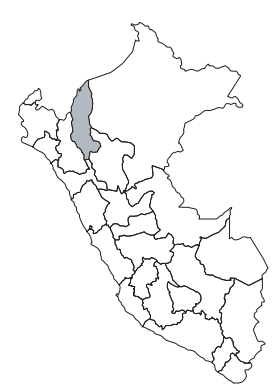

\section{Licania klugii Prance}

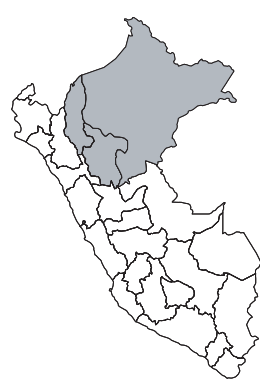

LC
Publicación: Fl. Neotrop. 9: 47—48, f. 6 A-D. 1972.

Colección tipo: G. Klug 2221

Herbarios: F, GH, K, MO, NY, US.

Nombre común: Egomana.

Registro departamental: AM, LO, SM.

Regiones Ecológicas: BHA; $180 \mathrm{~m}$.

SINANPE: Sin registro.

Herbarios peruanos: AMAZ (1), USM (1).

Observaciones: Especie arbórea conocida de varias localidades en la Amazonía peruana. El ejemplar tipo proviene de la cuenca del Putumayo, muy cerca al límite con Colombia. Ha sido recolectada de las cuencas del Imaza, Huallaga, Napo, entre otros. Vásquez (1997) menciona que crece en bosques con protección privada (Explornapo y Explorama Camp).

\section{Licania trigonioides J.F. Macbr.}

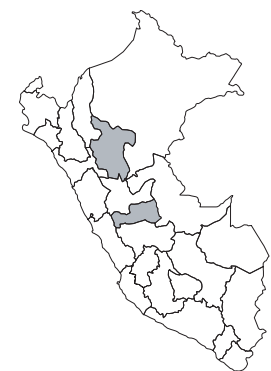

\section{DD}

Publicación: Fl. Neotrop. 9S: 20—22, f. 2, 38. 1989.

Colección tipo: A.H. Gentry et al. 25665

Herbarios: MO, NY; USM!.

Nombre común: Desconocido.

Registro departamental: PA, SM.

Regiones Ecológicas: BHA; $500 \mathrm{~m}$.

SINANPE: Sin registro.

Herbarios peruanos: USM (isotipo).

Observaciones: Esta especie arbórea es conocida de bosques de terraza, de dos localidades aisladas en las cuencas del Huallaga y del Palcazú respectivamente. Al parecer, no ha vuelto a ser recolectada desde 1986

\section{Licania intrapetiolaris Spruce ex Hook.f. var. brevis}

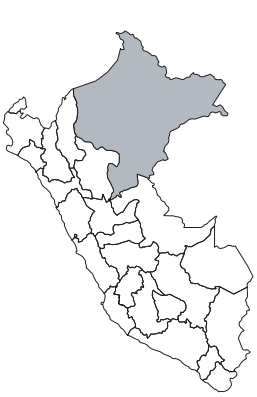

J.F. Macbr.

\section{DD}

Publicación: Candollea 5: 369. 1934.

Colección tipo: G. Klug 612

Herbarios: NY.

Nombre común: Desconocido.

Registro departamental: LO.

Regiones Ecológicas: BHA; 100-140 m.

SINANPE: Sin registro.

Herbarios peruanos: USM (1).

Observaciones: Especie arbórea conocida de poblaciones fragmentadas, en la Provincia de Maynas. Ha sido recolectada de bosques estacionalmente inundables, los cuales han sido escasamente herborizados.

\section{DD}

Publicación: Candollea 5: 368. 1934.

Colección tipo: G. Klug 449

Herbarios: F, NY, US.

Nombre común: Desconocido.

Registro departamental: LO.

Regiones Ecológicas: BHA; $100 \mathrm{~m}$.

SINANPE: Sin registro.

Herbarios peruanos: Ninguno.

Observaciones: Arbusto conocido aparentemente sólo de la colección tipo, una planta recolectada en 1929, de los alrededores de Iquitos.

\section{Licania vasquezii Prance}

\section{DD}

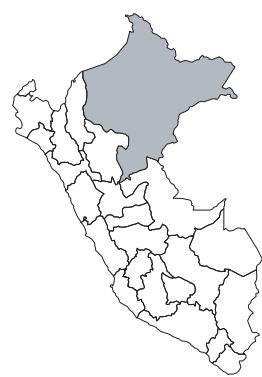

Publicación: Kew Bull. 47(2): 251—254, f. 4. 1992.

Colección tipo: R. Vásquez \& N. Jaramillo 12726

Herbarios: K, MO; USM!.

Nombre común: Desconocido.

Registro departamental: LO.

Regiones Ecológicas: BHA; 106 m.

SINANPE: Sin registro.

Herbarios peruanos: USM (isotipo).

Observaciones: Especie arbórea conocida solamente de la colección tipo, recolectada en 1989, en la cuenca del Amazonas, de un bosque parcialmente intervenido, cerca a los límites con Brasil y Colombia. 